\title{
Pengaruh Pendidikan Kesehatan Tentang Penatalaksanaan Non Farmakoterapi Hipertensi Terhadap Tingkat Pengetahuan Kader Di Desa Wedomartani, Ngemplak, Sleman, Yogyakarta
}

\author{
Cornelia D.Y Nekada*, I Gede Bayu Mahendra, Nazwar Hamdani Rahil, Thomas \\ Aquino Erjinyuare Amigo \\ Fakultas Ilmu Kesehatan, Universitas Respati Yogyakarta, Indonesia \\ *lia.nekada@gmail.com
}

\begin{abstract}
ABSTRAK
Hipertensi merupakan peningkatan tekanan darah diatas batas normal yaitu 140/90 mmHg. Hipertensi sering disebut sebagai silent killer dan tetap menjadi salah satu kontributor untuk penyakit kronis dan kematian. Pengobatan hipertensi dapat dilakukan melalui terapi farmakoterapi dan non farmakoterapi. Kurangnya pengetahuan masyarakat tentang non farmakoterapi hipertensi diharapkan melalui pendidikan kesehatan dapat meningkatkan pengetahuan masyarakat tentang penatalaksanaan non farmakoterapi hipertensi.

Mengetahui pengaruh pendidikan kesehatan tentang penatalaksanaan non farmakoterapi hipertensi terhadap tingkat pengetahuan kader di Desa Wedomartani, Ngemplak, Sleman, Yogyakarta.

Penelitian ini menggunakan rancangan pre and post test control group design yang dilaksanakan di Balai Desa Wedomartani, Ngemplak, Sleman, Yogyakarta dengan jumlah sampel yaitu 32 responden. Teknik sampling yang digunakan adalah cluster sampling. Analisa dengan menggunakan uji Wilcoxon. Instrumen yang digunakan adalah kuesioner pengetahuan.

Nilai median tingkat pengetahuan pre-test dan post-test pada kelompok intervensi yaitu 24,50 dan 28,00 . Nilai median tingkat pengetahuan pre-test dan post-test pada kelompok kontrol yaitu 26,00 dan 24,50. Hasil uji statistik tingkat pengetahuan pre-test dan post-test pada kelompok intervensi nilai $\mathrm{p}$ value 0,007 . dan kelompok kontrol didapatkan $\mathrm{p}$ value 0,314 . Ada pengaruh pendidikan kesehatan tentang penatalaksanaan non farmakoterapi hipertensi terhadap tingkat pengetahuan kader di Desa Wedomartani, Ngemplak, Sleman, Yogyakarta.
\end{abstract}

Kata Kunci: Pendidikan kesehatan, Penatalaksanaan non farmakoterapi hipertensi, Pengetahuan Kader

Received: June 28, 2020

Revised: July 18, 2020

Accepted: August 20, 2020

\section{(i) (2)}

This is an open-acces article distributed under the terms of the Creative Commons Attribution-ShareAlike 4.0 International License.

\section{PENDAHULUAN}

Hipertensi adalah peningkatan tekanan darah sistolik lebih dari $140 \mathrm{mmHg}$ dan atau tekanan diastolik lebih dari $90 \mathrm{mmHg}$ (Al Disi, Anwar, \& Eid, 2015). Hipertensi adalah penyakit kardiovaskuler yang paling banyak di dunia. Satu dari delapan seluruh kematian disebabkan oleh hipertensi dan menjadi urutan ke 3 penyebab mortalitas di dunia (Dipiro, et.al., 2008; Forouzanfar et al., 2017)). Data World Health Organization (WHO) angka prevalensi hipertensi di dunia dengan batasan berusia $\geq 25$ tahun terdiagnosa hipertensi 


\section{Journal of Community Engagement in Health}

http://jceh.org

ISSN: 2620-3758 (print); 2620-3766 (online)

https://doi.org/10.30994/jceh.v3i2.62

Vol.3 No.2. Sep 2020. Page.200-209

mengalami peningkatan dari 600 juta pada tahun 2008 menjadi 1 miliar pada tahun 2013 (WHO, 2013).

Berdasarkan data Riset Kesehatan Dasar (Riskesdas) pada tahun 2013, bahwa provinsi dengan prevalensi hipertensi ialah Sulawesi Utara (15,2\%), kemudian disusul Kalimantan Selatan (13,3\%), dan DI Yogyakarta (12,9\%), sedangkan prevalensi terendah terdapat di Papua $(3,3 \%)$, kemudian disusul oleh Papua Barat (5,2\%), dan Riau (6,1\%). Kenaikan prevalensi tertinggi terdapat di Sulawesi Barat, yakni $(9,6 \%)$ pada 2013 dan penurunan prevalensi terbanyak terdapat di Riau, yaitu $(6,1 \%)$.

Prevalensi hipertensi menurut Dinas Kesehatan Yogyakarta (Dinkes DIY) pada tahun 2016 adalah 35,8\% atau lebih tinggi dibandingkan dengan angka Nasional (31,7\%). Prevalensi ini menempatkan DIY pada urutan ke 5 sebagai provinsi dengan kasus hipertensi yang tinggi. Hipertensi selalu masuk dalam 10 besar penyakit sekaligus 10 besar penyebab kematian di DIY selama beberapa tahun terakhir berdasarkan Sistem Survailans Terpadu (STP). Laporan STP Puskesmas Tahun 2016 tercatat kasus hipertensi 29.105 kasus. Sedangkan laporan STP Rumah Sakit Rawat Jalan sebanyak 1.152 kasus hipertensi essensial (Dinkes DIY, 2016).

Hipertensi dapat menyebabkan banyak komplikasi, termasuk infark miokard (MI), penyakit ginjal kronis (CKD), penyakit serebrovaskular, retinopati, dan gagal jantung (Klabunde, 2015; Price, 2010). Hal ini sering disebut sebagai silent killer dan tetap menjadi salah satu kontributor paling signifikan untuk penyakit kronis dan kematian (Abel, Contino, Jain, Grewal, Grand, Hagans, Hunter, Roy, 2017) . Namun masih banyak penderita hipertensi yang kurang memahami cara pengobatan, pencegahan, maupun mengontrol penyakit yang diderita karena kurang terpapar informasi kesehatan (Novian, 2014; Thankappan, Sivasankaran, Mini, Daivadanam, Sarma, \& Abdul Khader, 2013).

Pengobatan hipertensi dapat dilakukan melalui terapi farmakoterapi dan non farmakoterapi untuk mengontrol tekanan darah (Wasito, 2011). Terapi non farmakoterapi dilakukan dengan modifikasi gaya hidup, yaitu menurunkan berat badan, latihan fisik secara teratur, mengurangi asupan garam, berhenti minum alkohol, berhenti merokok diet kolesterol atau lemak jenuh (Dewanti, Andrajti, Supardi, 2015). Sebagai salah satu alternatif pengobatan non farmakoterapi hipertensi, dengan memanfaatkan tanaman herbal diharapkan dapat menjadi sebuah terobosan baru dalam mengatasi permasalahan hipertensi (Kharisna, Dewi, Lestari, 2012). Upaya yang dapat dilakukan untuk meningkatkan pemahaman tentang hipertensi yaitu dengan pendidikan kesehatan. Pendidikan kesehatan adalah suatu kegiatan atau usaha untuk menyampaikan pesan kesehatan kepada masyarakat, kelompok atau individu. Dengan harapan bahwa dengan adanya pesan tersebut masyarakat, kelompok atau individu dapat memperoleh pengetahuan tentang kesehatan yang lebih baik (Notoatmodjo, 2010).

Promosi kesehatan tidak dapat berjalan sebagaimana yang diharapkan tanpa adanya dukungan dari masyarakat, kelompok masyarakat yang ditunjuk sebagai media penyampai langsung dalam promosi kesehatan adalah kader atau orang yang ditunjuk untuk membantu pelaksanaan posyandu. (Thankappan, Sivasankaran, Mini, Daivadanam, Sarma, \& Abdul Khader, 2013). Upaya kesehatan yang dilakukan oleh kader dalam posyandu memiliki peranan yang sangat penting dalam mengupayakan cakupan dalam kegiatan promosi kesehatan meliputi pendidikan kesehatan. Peran dan tugas kader dalam menggerakkan masyarakat membantu petugas kesehatan dalam memberikan informasi serta penyuluhan kesehatan yang jelas dan mudah dimengerti bagi masyarakat (Setyoadi., Ahsan., Abidin, 2013). 


\section{Journal of Community Engagement in Health}

http://jceh.org

ISSN: 2620-3758 (print); 2620-3766 (online)

https://doi.org/10.30994/jceh.v3i2.62

Vol.3 No.2. Sep 2020. Page.200-209

\section{PERMASALAHAN MITRA}

Berdasarkan studi pendahuluan yang dilakukan peneliti di Kantor Desa Wedomartani, Ngemplak, Sleman, Yogyakarta pada tanggal 30 Oktober 2017 terdapat jumlah kader kesehatan 323 orang. Desa Wedomartani terdapat 25 padukuhan dan memiliki 47 posyandu dari padukuhan tersebut. Sebagian besar kader di Desa Wedomartani memiliki tingkat pendidikan terakhir SMA. Berdasarkan hasil wawancara peneliti dengan 30-40 orang kader tentang pengetahuan bagaimana penatalaksanaan non farmakoterapi hipertensi. Hasil yang didapatkan kader belum tahu secara menyeluruh tentang penatalaksanaan non farmakoterapi untuk pasien hipertensi. Dan hasil informasi yang didapatkan bahwa untuk pendidikan kesehatan tentang hipertensi dari puskesmas Ngemplak II dilakukan 2-3 kali setahun, kader yang diundang secara bergantian. Data yang diperoleh peneliti dari Puskesmas Ngemplak II, Puskesmas pembantu I Wedomartani dan Puskesmas Pembantu II Wedomartani didapatkan data jumlah kunjungan pasien penderita hipertensi dari bulan Januari-Oktober 2017 berjumlah 490 orang.

\section{METODE PELAKSANAAN}

Populasi target dalam kegiatan pengabdian ini adalah seluruh kader yang ada di Desa Wedomartani yang berjumlah 323 kader kesehatan. Kegiatan pengabdian ini diberikan kepada 32 kader yang dibagi menjadi 2 kelompok intervensi dan kontrol. Hasil pengabdian ini, kemudian diteliti menggunakan rancangan pre and post test control group design. (Dharma, 2011). Kegiatan pengabdian ini dilaksanakan di Aula Balai Desa Wedomartani, Ngemplak, Sleman, Yogyakarta pada tanggal 10 Maret 2018. Teknik sampling yang digunakan adalah cluster sampling, yaitu mengambil perwakilan kader kesehatan dari masing-masing padukuhan. Analisa bivariat dengan menggunakan uji Wilcoxon. Instrumen yang digunakan dalam penelitian ini adalah kuesioner pengetahuan tentang penatalaksanaan non farmakoterapi hipertensi, yang valid dan reliabel.

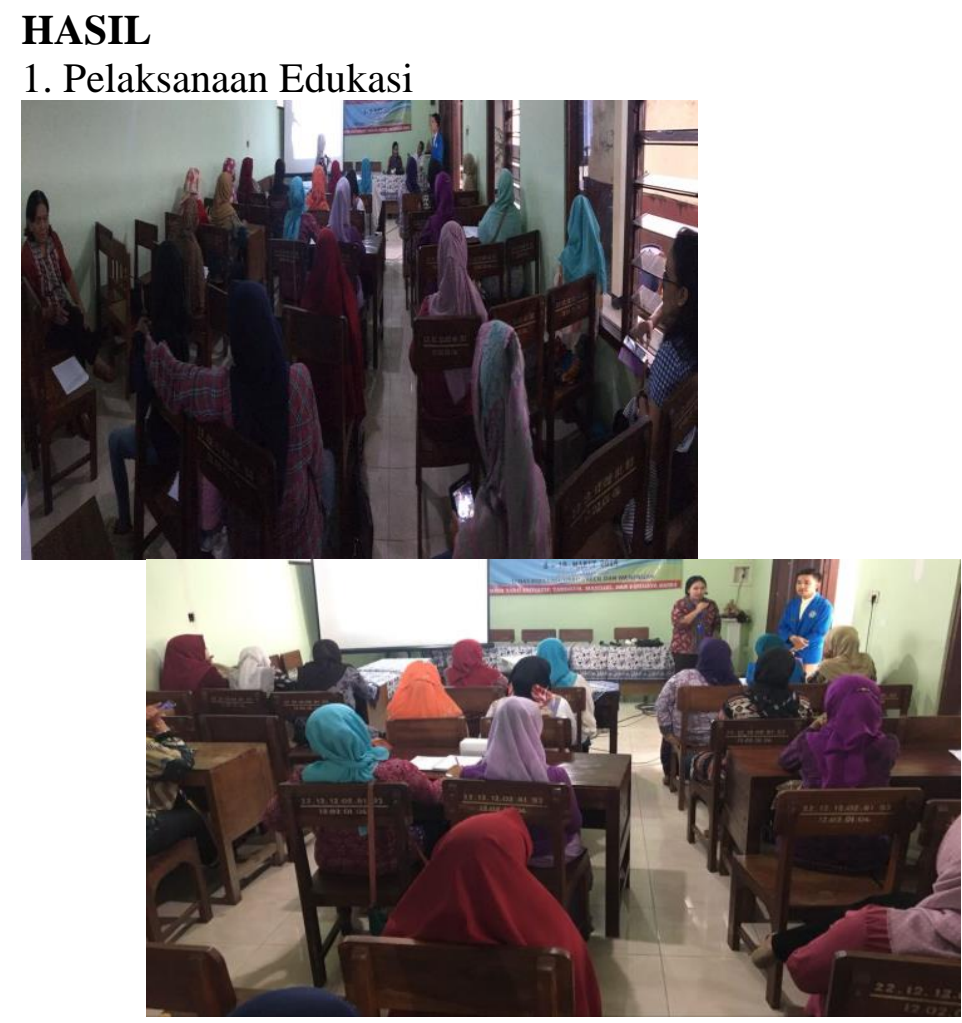




\section{Journal of Community Engagement in Health}

http://jceh.org

ISSN: 2620-3758 (print); 2620-3766 (online)

https://doi.org/10.30994/jceh.v3i2.62

Vol.3 No.2. Sep 2020. Page.200-209

2. Pelatihan Pembuatan Jus Mentimun Untuk Pasien Hipertensi
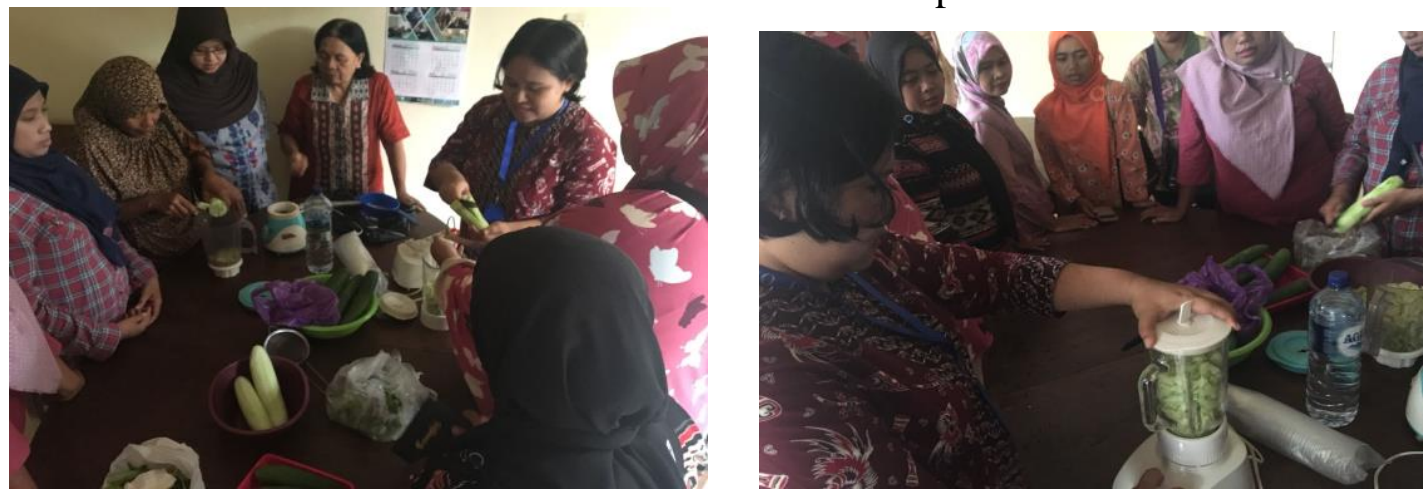

\section{Analisa Univariat}

Karakteristik responden meliputi umur, tingkat pendidikan dan pekerjaan. Data tentang frekuensi karakteristik responden disajikan pada tabel 1.

\section{Tabel 1}

Distribusi Frekuensi Karakteristik Responden pada kelompok intervensi dan Kelompok kontrol Berdasarkan Umur, tingkat pendidikan dan pekerjaan Kader di Desa Wedomartani, Ngemplak, Sleman, Yogyakarta

\begin{tabular}{lcccc}
\hline \multirow{2}{*}{ Karakteristik } & \multicolumn{2}{c}{$\begin{array}{c}\text { Intervensi } \\
(\mathbf{n = 1 6})\end{array}$} & \multicolumn{2}{c}{$\begin{array}{c}\text { Kontrol } \\
(\mathbf{n = 1 6})\end{array}$} \\
\cline { 2 - 5 } & $\mathbf{f}$ & $\mathbf{\%}$ & $\mathbf{f}$ & $\mathbf{\%}$ \\
\hline Umur & & & & \\
Remaja akhir & 1 & 6,3 & 0 & 0 \\
Dewasa awal & 2 & 12,6 & 3 & 18,8 \\
Dewasa akhir & 7 & 43,9 & 9 & 56,0 \\
Lansia awal & 6 & 37,8 & 3 & 18,9 \\
Lansia akhir & 0 & 0 & 1 & 6,3 \\
\hline Pendidikan & & & & \\
SMP & 1 & 6,3 & 2 & 12,5 \\
SMA & 9 & 56,3 & 10 & 62,5 \\
D3 & 1 & 6,3 & 0 & 0 \\
S1 & 5 & 31,3 & 4 & 25,0 \\
\hline Pekerjaan & \multicolumn{4}{|c}{} \\
Bekerja & 3 & 18,8 & 3 & 18,8 \\
Tidak Bekerja & 13 & 81,3 & 13 & 81,3 \\
\hline \multicolumn{1}{c}{ Sumber Data: Data Primer (diolah tahun 2018) }
\end{tabular}

Berdasarkan tabel 1 diketahui pada kelompok intervensi berdasarkan umur responden paling banyak berusia 36-45 tahun (dewasa akhir) yaitu sebanyak 7 orang (43,9\%). Sedangkan pada kelompok kontrol berdasarkan umur responden sebagian besar berusia 3645 tahun (dewasa akhir) yaitu sebanyak 9 orang $(56,0 \%)$. Berdasarkan tingkat pendidikan pada kelompok intervensi sebagian besar responden tingkat pendidikan SMA yaitu sebanyak 9 responden (56,3\%). Pada kelompok kontrol berdasarkan tingkat pendidikan sebagian besar responden tingkat pendidikan SMA yaitu sebanyak 10 responden $(62,5 \%)$. 
Sedangkan berdasarkan pekerjaan pada kelompok intervensi dan kelompok kontrol mayoritas responden tidak bekerja yaitu 13 responden $(81,3 \%)$.

Hasil analisis tingkat pengetahuan responden pada pre-test dan post-test pada kelompok intervensi maupun kelompok kontrol dapat dilihat pada tabel 2.

\section{Tabel 2}

Distribusi Tingkat Pengetahuan Pre-test dan Post-test Pada Kelompok Intervensi dan Kelompok Kontrol

\begin{tabular}{lcccc}
\hline Kelompok & N & $\begin{array}{c}\text { Media } \\
\text { n }\end{array}$ & Min & Max \\
\hline Pre test & & & & \\
Intervensi & 16 & 24,50 & 21 & 29 \\
Kontrol & 16 & 26,00 & 19 & 29 \\
\hline Post test & & & & \\
Intervensi & 16 & 28,00 & 17 & 30 \\
Kontrol & 16 & 24,50 & 20 & 28 \\
\hline Sumber Data:
\end{tabular}

Sumber Data: Data Primer (diolah tahun 2018)

Berdasarkan tabel 2 diketahui tingkat pengetahuan pre-test pada kelompok intervensi nilai minimal 21 dan maksimal 29 dengan nilai median sebesar 24,50, sedangkan tingkat pengetahuan pada kelompok kontrol nilai minimal 19 dan maksimal 29 dengan nilai median sebesar 26,00. Sementara untuk tingkat pengetahuan post-test pada kelompok intervensi nilai minimal 17 dan maksimal 30 dengan nilai median adalah 28,00, sedangkan tingkat pengetahuan pada kelompok kontrol nilai minimal 20 dan maksimal 28 dengan nilai median adalah 24,50 .

\section{Analisa bivariat}

Sebelum peneliti melakukan analisa bivariat, bahwa data yang telah dikumpulkan dilakukan uji normalitas. uji normalitas untuk pre-test pada kelompok intervensi sebesar 0,337 dan untuk post-test sebesar 0,007. Oleh karena itu data tidak berdistribusi normal. Sedangkan pre-test pada kelompok kontrol sebesar 0,033 dan post-test sebesar 0,039. Maka dapat diambil kesimpulan bahwa data tidak berdistribusi normal, maka uji yang dapat digunakan peneliti menggunakan uji wilcoxon.

Hasil uji pengaruh pendidikan kesehatan tentang penatalaksanaan non farmakoterapi hipertensi terhadap tingkat pengetahuan pre-test dan post-test kelompok kontrol dan kelompok intervensi dapat dilihat pada tabel 3.

\section{Tabel 3}

Pengaruh Pendidikan Kesehatan Tentang Penatalaksanaan Non Farmakoterapi Hipertensi Terhadap Tingkat Pengetahuan Kader di Desa Wedomartani, Ngemplak, Sleman, Yogyakarta

\begin{tabular}{|c|c|c|c|c|}
\hline \multirow[b]{2}{*}{ Kelompok } & \multicolumn{2}{|c|}{ Median } & \multirow[b]{2}{*}{$\begin{array}{c}\text { Selisih } \\
\text { Median }\end{array}$} & \multirow{2}{*}{$\begin{array}{c}P \\
\text { value }\end{array}$} \\
\hline & $\begin{array}{l}\text { Pre- } \\
\text { test }\end{array}$ & $\begin{array}{c}\text { Post- } \\
\text { test }\end{array}$ & & \\
\hline Inte & 24,50 & 28,00 & 3, & 0,007 \\
\hline Kontrol & 26,00 & 24,50 & $-1,5$ & 0,314 \\
\hline
\end{tabular}

Sumber Data: Data Primer (diolah tahun 2018)* uji Wilcoxon 


\section{Journal of Community Engagement in Health}

Berdasarkan tabel 3 diketahui bahwa tingkat pengetahuan pada kelompok intervensi diketahui bahwa nilai median pre-test sebesar 24,50 dan nilai median post-test sebesar 28,00 dengan selisih median sebesar 3,5. Nilai $p$ value $0,007<0,05$ maka secara statistik ada perbedaan tingkat pengetahuan pre-test dan post-test pada kelompok intervensi. Sedangkan tingkat pengetahuan pada kelompok kontrol nilai median pre-test 26,00 dan post-test sebesar 24,50 dengan selisih median -1,5. Nilai $p$-value 0,314>0,05. Maka secara statistik tidak ada perbedaan tingkat pengetahuan pre-test dan post-test pada kelompok kontrol.

\section{PEMBAHASAN}

Tingkat Pengetahuan Pre-test dan Post-test Pada Kelompok Intervensi dan Kelompok Kontrol

Hasil tingkat pengetahuan pre-test pada kelompok intervensi nilai terendah 21 dan tertinggi 29 dengan nilai median sebesar 24,50, sedangkan hasil tingkat pengetahuan posttest nilai terendah 17 dan tertinggi 30 dengan nilai median sebesar 28,00. Sementara hasil tingkat pengetahuan pre-test pada kelompok kontrol nilai terendah 19 dan nilai tertinggi 29 dengan nilai median adalah 26,00, sedangkan tingkat pengetahuan post-test yaitu nilai terendah 20 dan nilai tertinggi 28 dengan nilai median adalah 24,50. Hasil ini menunjukan pada kelompok intervensi saat pre-test tingkat pengetahuan kader tentang penatalaksnaan non farmakoterapi hipertensi belum mengetahui secara benar terkait dengan definisi non farmakoterapi hipertensi, diet hipertensi, pola aktivitas dan terapi herbal hipertensi.

Sebuah teori mengatakan bahwa faktor-faktor yang mempengaruhi pengetahuan seseorang ada dua, yaitu faktor internal (umur, pendidikan, pekerjaan) dan faktor eksternal (faktor lingkungan dan sosial budaya) (Edward et al., 2020). Faktor umur dapat mempengaruhi pengetahuan, dalam penelitian ini paling banyak umur responden pada kelompok intervensi berusia 36-45 tahun sebanyak 43,9\% dan pada kelompok kontrol sebagian besar berusia 36-45 tahun sebanyak 56,0\% yaitu termasuk kategori dewasa akhir. Hasil ini menunjukan semakin cukup umur seseorang maka tingkat kematangan dan kekuatan seseorang akan lebih matang dalam berpikir dan bekerja (Wawan \& Dewi, 2010).

Hasil penelitian ini sejalan dengan penelitian lain, yang menyatakan sebagian besar responden merupakan kelompok dewasa akhir yang telah memiliki tanggung jawab terhadap keluarga dan orang lain. (Legido et al., 2019) Umur seseorang pada umumnya berhubungan dengan tingkat pengetahuan. Semakin cukup umur responden maka akan lebih mudah dalam menerima informasi (Kurniawan, 2017). Umur merupakan faktor yang mempengaruhi pengetahuan artinya semakin bertambah umur akan semakin berkembang pula daya tangkap dan pola pikir orang tersebut (Notoatmodjo, 21010).

Berdasarkan hasil dari penelitian ini secara statistik dapat disimpulkan bahwa umur kader di Desa Wedomartani Ngemplak Sleman Yogyakarta pada kelompok intervensi ratarata berumur 36-45 tahun termasuk dewasa akhir. Secara psikologis telah memiliki kematangan dalam berpikir secara rasional untuk menerima pengetahuan tentang penatalaksanaan non farmakoterapi hipertensi.

Berdasarkan faktor pendidikan yang mempengaruhi pengetahuan seseorang, hasil penelitian ini menunjukan pada kelompok intervensi sebagian besar responden berpendidikan SMA sebanyak 56,3\%. Sedangkan pada kelompok kontrol sebagian besar responden berpendidikan SMA sebanyak 62,5\%. Teori lain mengatakan sebagian besar responden mempunyai pendidikan menengah (SMA). Hasil tingkat pendidikan yang dimiliki responden cukup mendukung untuk memahami informasi dari pendidikan kesehatan dan meningkatkan pengetahuan (Kurniawan, 2017). 


\section{Journal of Community Engagement in Health}

http://jceh.org

ISSN: 2620-3758 (print); 2620-3766 (online)

https://doi.org/10.30994/jceh.v3i2.62

Vol.3 No.2. Sep 2020. Page.200-209

Menurut teori mengatakan bahwa tingkat pendidikan dapat meningkatkan pengetahuan tentang kesehatan. (C.-H. Lu et al., 2015). Pendidikan merupakan hal yang sangat penting dalam mempengaruhi pikiran seseorang. Orang yang berpendidikan baik cenderung akan mampu berpikir tenang terhadap suatu masalah. Orang dengan tingkat pendidikan yang tinggi akan mudah menerima informasi yang diterima sehingga dapat mengetahui dan memahami tentang penatalaksnaan non farmakoterapi hipertensi (Novita, 2013). Pendidikan dapat mempengaruhi cara pandang seseorang. Pada umumnya makin tinggi pendidikan seseorang, maka makin mudah menerima informasi yang baru demikian sebaliknya semakin rendah pendidikan seseorang maka akan sulit menerima informasi (Notoatmodjo, 21010).

Faktor pekerjaan juga dapat mempengaruhi pengetahuan seseorang, hasil penelitian ini menunjukan pada kelompok intervensi mayoritas responden tidak bekerja sebesar 81,3\%. Sedangkan pada kelompok kontrol mayoritas responden tidak bekerja sebesar 81,3\%. Pada penelitian ini mayoritas kader tidak bekerja atau sebagai ibu rumah tangga. Kader yang bekerja sebagai Ibu Rumah Tangga seharusnya mempunyai pengetahuan yang lebih baik dari kader yang bekerja di luar rumah. Hal ini karena kader sebagai ibu rumah tangga lebih banyak memiliki waktu yang lebih dalam kegiatan posyandu. Walaupun responden mayoritas sebagai ibu rumah tangga, jika didalam padukuhan kader dan posyandunya kurang aktif hal tersebut tidak akan mempengaruhi tingkat pengetahuan kader (Rofif, 2016).

Pengaruh Pendidikan Kesehatan tentang Penatalaksanaan Non Farmakoterapi Hipertensi Terhadap Tingkat Pengetahuan

Berdasarkan tabel 3 diketahui bahwa tingkat pengetahuan pada kelompok intervensi pre-test dan post-test menggunakan uji wilcoxon diperoleh $p$-value $0,007<0,05$. Maka secara statistik ada perbedaan tingkat pengetahuan pre-test dan post-test pada kelompok intervensi. Hasil ini menunjukan terjadi perubahan tingkat pengetahuan sesuai yang diharapkan melalui pendidikan kesehatan tentang penatalaksanaan non farmakoterapi hipertensi pada kader di Desa Wedomartani. Pendidikan kesehatan merupakan suatu kegiatan atau usaha untuk menyampaikan pesan kesehatan kepada masyarakat, kelompok atau individu (Notoatmodjo, 21010). Dengan harapan bahwa dengan adanya pesan tersebut masyarakat, kelompok atau individu dapat memperoleh pengetahuan tentang kesehatan yang lebih baik. (Irani, 2019). Setelah diberikannya pendidikan kesehatan tentang penatalaksanaan non farmakoterapi hipertensi pada kelompok intervensi terdapat perbedaan tingkat pengetahuan pre-test dan post test sesuai yang diharapkan.

Hasil penelitian juga didukung oleh penelitian lain, dengan hasil yang menunjukan bahwa ada perbedaan nilai rata-rata pre-test dan post-test menggunakan metode ceramah serta membagikan leaflet dan kuesioner (Dungga, 2014). Dalam penelitian ini pemberian pendidikan kesehatan menggunakan metode ceramah terhadap pengetahuan seseorang sangat efektif. Pendidikan kesehatan merupakan salah satu bentuk strategi intervensi atau upaya yang dilakukan dalam pelayanan keperawatan komunitas. Pendidikan kesehatan juga dapat memberikan informasi yang sesuai dan spesifik sehingga dapat meningkatkan pengetahuan seseorang (Widyanto, 2014).

Pemberian pendidikan kesehatan menggunakan salah satunya yaitu metode ceramah serta alat bantu, misalnya makalah singkat, slide, sound system, leaflet, dan sebagainya. Hal ini terbukti bahwa pendidikan kesehatan cukup efektif dan efisien serta memberikan pengaruh untuk meningkatkan pengetahuan kader dalam jangka waktu yang singkat dan sesuai teori yang sudah ada, selain itu penyampaian materi yang menarik dan bahasa 


\section{Journal of Community Engagement in Health}

penyampaian yang disesuaikan dengan tingkat pendidikan, umur responden berpengaruh terhadap peningkatan pengetahuan responden (Nursalam \& Efendi). Sedangkan tingkat pengetahuan pada kelompok kontrol pre-test dan post-test menggunakan uji wilcoxon diperoleh $p$-value 0,314 >0,05. Maka secara statistik tidak ada perbedaan tingkat pengetahuan pre-test dan post-test pada kelompok kontrol. Hal ini karena kelompok kontrol hanya sebagai pembanding dan tidak mendapatkan informasi terkait dengan pendidikan kesehatan tentang penatalaksnaan non farmakoterapi hipertensi. Hasil penelitian ini sesuai dengan penelitian lain, bahwa penelitian tersebut mengatakan tidak ada perbedaan tingkat pengetahuan pre-test dan post-test dengan $p$ value 0,157 . Hal ini karena pada kelompok kontrol tidak mendapatkan intervensi pendidikan kesehatan sehingga tidak ada peningkatan tingkat pengetahuan pre-test dan post-test pada responden (Muliana, 2014).

Berdasarkan hasil penelitian didapatkan hasil bahwa ada perbedaan tingkat pengetahuan pre-test dan post-test pada kelompok intervensi dan tidak ada perbedaan tingkat pengetahuan pada kelompok kontrol. Hasil tingkat pengetahuan kelompok intervensi didapatkan nilai median pre-test sebesar 24,50 sedangkan nilai median post-test sebesar 28,00 dengan selisih median atau peningkatan skor 3,5. Peningkatan tersebut disebabkan karena diberikannya intervensi yaitu pendidikan kesehatan tentang penatalaksanaan non farmakoterapi hipertensi pada kader di Desa Wedomartani Ngemplak Sleman Yogyakarta. Dari hasil perbedaan yang telah dijelaskan sebelumnya tingkat pengetahuan pre-test dan post-test pada kelompok intervensi menandakan ada pengaruh pendidikan kesehatan tentang penatalaksanaan non farmakoterapi hipertensi terhadap tingkat pengetahuan kader di Desa Wedomartani Ngemplak Sleman Yogyakarta. Hal ini juga sesuai dengan penelitian yang dilakukan Jafar et al (2017) bahwa untuk mengatasi hipertensi tidak hanya dengan obat-obatan namun perlu juga dukungan sosial, dengan adanya dukungan dari orang disekitar orang dengan hipertensi akan menjadi semangat untuk mematuhi terapi yang diberikan dan menjaga kondisi kesehatannya. Tambahan informasi yang diberikan melalui kegiatan ini telah terbukti mampu memberikan gambaran informasi penatalaksanaan non farmakoterapi untuk pasien hipertensi. Kegiatan ini juga mengajarkan para kader untuk membuat jus mentimun sebagai salah satu terapi non farmakologis untuk pasien hipertensi (Nurhidayat, 2012). Selain jus mentimun sesungguhnya ada jus lain yang bisa dimanfaatkan untuk pasien hipertensi yaitu jus semangka (Shanti \& Zuraida, 2016).

Sesuai dengan teori menyatakan faktor-faktor yang mempengaruhi keberhasilan pendidikan kesehatan diantaranya adalah faktor pemateri, saran prasarana dan proses pendidikan kesehatan (Machfoedz, 2019). Berdasarkan hasil dari penelitian ini peneliti memberikan kesimpulan bahwa pelaksanaan pendidikan kesehatan dengan menggunakan metode ceramah dengan alat bantu LCD dapat meningkatkan pengetahuan dan pemahaman kader tentang penatalaksanaan non farmakoterapi hipertensi sehingga kader dapat mengetahui dan memahami secara jelas mengenai definisi non farmakoterapi hipertensi, diet hipertensi, pola aktivitas dan terapi herbal hipertensi.

\section{KESIMPULAN DAN SARAN}

Hasil dari kegiatan pengabdian ini menunjukkan bahwa ada pengaruh pendidikan kesehatan tentang penatalaksanaan non farmakoterapi hipertensi terhadap tingkat pengetahuan kader di Desa Wedomartani Ngemplak Sleman Yogyakarta. Sehingga berdasarkan hasil kegiatan tersebut maka saran yang dapat kami berikan antara lain bagi kader kesehatan yaitu mampu menerapkan hasil pendidikan kesehatan tentang 


\section{Journal of Community Engagement in Health}

http://jceh.org

ISSN: 2620-3758 (print); 2620-3766 (online)

https://doi.org/10.30994/jceh.v3i2.62

Vol.3 No.2. Sep 2020. Page.200-209

penatalaksanaan herbal pada kondisi hipertensi dalam kegiatan posyandu atau di masyarakat, dan untuk perawat komunitas mampu melakukan pendampingan terkait dengan penerapan penatalaksanaan herbal penyakit-penyakit lain selain hipertensi

\section{DAFTAR PUSTAKA}

Abel, N., Contino,K., Jain, N., Grewal, N., Grand, E., Hagans, I., Hunter, K., Roy, S. (2017). Eighth Joint National Committee (JNC-8) Guidelines and the Outpatient Management of Hypertension in the African-American Population. North American Journal of Medical Sciences Oct 2015 Volume 7 Issue 10.

Al Disi, S. S., Anwar, M. A., \& Eid, A. H. (2015). Anti-hypertensive Herbs and their Mechanisms of Action: Part I. Frontiers in Pharmacology, 6, 323.

Dewanti, S.W., Andrajti, R., Supardi, S. (2015). Pengaruh Konseling dan Leaflet terhadap Efikasi Diri,, Jurnal Kefarmasian Indonesia. Diakses pada 30 September 2017.

Dharma, K. (2011). Metodologi Penelitian Keperawatan. Depok : CV. Trans Info Media.

Dinkes DIY. (2016). Profil Kesehatan Daerah Istimewa Yogyakarta Tahun 2016. Dinas Kesehatan Daerah Istimewa Yogyakarta Tahun Anggaran 2017.

Dipiro, Saseen JJ, Mc Laughlin EJ .(2008). Pharmacotherapy A Phatophysiologic. New York: Mc Graw Hill, New York.

Dungga, L. (2014). Pengaruh Penyuluhan Kesehatan Tetang Bahaya Obesitas pada Anak Usia 11 Tahun Terhadap Sikap Anak Tentang Pencegahan Obesitas Di SDN Kledokan Depok Sleman Yogyakarta.Skripsi. UNRIYO.

Edward, A., Hoffmann, L., Manase, F., Matsushita, K., Pariyo, G., Brady, T., \& Appel, L. (2020). An Exploratory Study on the Quality of Patient Screening and Counseling for Hypertension Management in Tanzania. PLOS ONE, 15, e0227439.

Forouzanfar, M. H., Liu, P., Roth, G. A., Ng, M., Biryukov, S., Marczak, L., Alexander, L., et al. (2017). Global Burden of Hypertension and Systolic Blood Pressure of at Least 110 to $115 \mathrm{~mm} \mathrm{Hg}, 1990-2015$. JAMA, 317(2), 165-182.

Irani, N. (2019). Analysis Relationship Family Support and Health Cadre with Elderly Hypertension Practice in Controlling Health at Primary Health Care Mranggen Demak. South East Asia Nursing Research, 1, 7.

Jafar, T. H., Jehan, I., de Silva, H. A., Naheed, A., Gandhi, M., Assam, P., Finkelstein, E. A., et al. (2017). Multicomponent intervention versus usual care for management of hypertension in rural Bangladesh, Pakistan and Sri Lanka: Study protocol for a cluster randomized Controlled Trial. Trials, 18(1), 272.

Kharisna, D., Dewi, W.N., Lestari, W. (2012). Efektifitas Konsumsi Jus Mentimun Terhadap, Jurnal Ners Indonesia, Vol. 2, No. 2. Diakses pada 01 Oktober 2017.

Klabunde, R. E. (2015). Konsep Fosiologi Kardiovaskular. Jakrta : EGC

Kurniawan, A. (2017). Hubungan Tingkat Pengetahuan Dan Efikasi Diri Dengan Pelayanan Kader Posyandu Lansia Di Desa Mancasan Kecamatan Baki. Skripsi. Universitas muhammadiyah surakarta.

Legido-Quigley H, Naheed A, de Silva HA, Jehan I, Haldane V, Cobb B, et al. (2019) Patients' experiences on accessing health care services for management of hypertension in rural Bangladesh, Pakistan and Sri Lanka: A qualitative study. PLoS ONE 14(1): e0211100. https://doi.org/10.1371/journal.pone.0211100

Lu, C.-H., Tang, S.-T., Lei, Y.-X., Zhang, M.-Q., Lin, W.-Q., Ding, S.-H., \& Wang, P.-X. (2015). Community-Based Interventions in Hypertensive Patients: A Comparison of Three Health Education Strategies. BMC public health, 15, 33. 


\section{Journal of Community Engagement in Health}

http://jceh.org

ISSN: 2620-3758 (print); 2620-3766 (online)

https://doi.org/10.30994/jceh.v3i2.62

Vol.3 No.2. Sep 2020. Page.200-209

Machfoedz, I. (2009). Pendidikan Kesehatan Bagian dan Promosi Kesehatan. Yogyakarta: Fitramaya.

Muliana, M. (2014). Pengaruh Pendidikan Kesehatan Terhadap Tingkat Pengetahuan Dan Sikap Remaja Sma X Dalam Upaya Pencegahan Hiv/Aids Di Kabupaten Karanganyar. Skripsi. Universitas Muhammadiyah Surakarta.

Notoatmodjo, S. (2010). Metodologi Penelitian Kesehatan. Jakarta: Rineka Cipta

Novian, A. (2014). Faktor Yang Berhubungan Dengan Kepatuhan Diit Pasien Hipertensi. Unnes Journal of Public Health 3 (3). http://journal.unnes.ac.id/sju/index.php/ujph. diakses pada 30 September 2017.

Novita, M. R. (2013). Pengaruh Pendidikan Kesehatan Terhadap Pengetahuan Ibu Terhadap Kandungan Air Susu Ibu Di Desa Kaliwuluh Kebakkramat Karanganyar. Jurnal keperawatan UMS.

Nurhidayat, S. (2012). Efektivitas Jus Mentimun Terhadap Penurunan Tekanan Darah Tinggi Pada Penderita Hipertensi. diakses pada 20 Desember 2017.

Nursalam \& Efendi, F. (2012). Pendidikan Dalam Keperawatan. Jakarta: Salemba Medika. Price, A Sylvia. 2010. Pathofisiologi. Edisi 4. Jilid I. Jakarta. EGC

Riset Kesehatan Dasar (Riskesdas). 2013. Buku Profil Kesehatan 2013. Badan Litbangkes Kemenkes RI.

Rofif, et al. (2016). Pengaruh Pendidikan Perawatan Bayi Baru Lahir Dengan Metode Syndicate Group Terhadap Pengetahuan Kader Posyandu Di Desa Sumberdanti Wilayah Kerja Puskesmas Sukowono Kabupaten Jember. Jurnal Pustaka Kesehatan, vol.4 (no.3).

Setyoadi., Ahsan., Abidin, A.Y. (2013). Hubungan Peran Kader Kesehatan Dengan Tingkat Kualitas Hidup Lanjut Usia. Jurnal Ilmu Keperawatan, Vol: 1, No. 2. www.jik.ub.ac.id. Diakses pada 14 Oktober 2017.

Shanti, N. M \& Zuraida, R. (2016). Pengaruh Pemberian Jus Semangka Terhadap Penurunan Tekanan Darah Lansia. Volume 5 : Nomor 4. Diakses pada 29 November 2017

Thankappan, K. R., Sivasankaran, S., Mini, G. K., Daivadanam, M., Sarma, P. S., \& Abdul Khader, S. (2013). Impact of a Community Based Intervention Program on Awareness, Treatment and Control of Hypertension in a Rural Panchayat, Kerala, India. Indian Heart Journal, 65(5), 504-509.

Wasito, H. (2011). Obat Tradisional Kekayaan Indonesia. Yogyakarta; Graha Ilmu

Wawan \& Dewi. (2010). Teori \& Pengeukuran Penegtahuan, Sikap, Dan Prilaku Manusia. Yogyakarta: Nuha Medika.

Widyanto, F. C. (2014). Keperawatan Komunitas Dengan Pendekatan Praktis. Yogyakarta: Nuha Medika.

World Health Organization. (2013). A Gobal Brief on Hypertension: Silent Killer. Global Public Health Crisis. Switzerland: World Health Organization. 